\title{
TEACHING MATHEMATICS USING MASSIVE OPEN ONLINE COURSES
}

\author{
Filomena Soares ${ }^{1}$, Ana Paula Lopes ${ }^{2}$ \\ ${ }^{1}$ Polytechnic Institute of Porto (IPP) / ESEIG (PORTUGAL) \\ ${ }^{2}$ Polytechnic Institute of Porto (IPP) / ISCAP - CICE / UIE (PORTUGAL)
}

\begin{abstract}
Distance learning - where students take courses (attend classes, get activities and other sort of learning materials) while being physically separated from their instructors, for larger part of the course duration - is far from being a "new event". Since the middle of the nineteenth century, this has been done through Radio, Mail and TV, taking advantage of the full educational potential that these media resources had to offer at the time. However, in recent times we have, at our complete disposal, the "magic wonder" of communication and globalization - the Internet. Taking advantage of a whole new set of educational opportunities, with a more or less unselfish "look" to economic interests, focusing its concern on a larger and collective "welfare", contributing to the development of a more "equitable" world, with regard to educational opportunities, the Massive Open Online Courses (MOOCs) were born and have become an important feature of the higher education in recent years. Many people have been talking about MOOCs as a potential educational revolution, which has arrived from North America, still growing and spreading, referring to its benefits and/or disadvantages.
\end{abstract}

The Polytechnic Institute of Porto, also known as IPP, is a Higher Education Portuguese institution providing undergraduate and graduate studies, which has a solid history of online education and innovation through the use of technology, and it has been particularly interested and focused on MOOC developments, based on an open educational policy in order to try to implement some differentiated learning strategies to its actual students and as a way to attract future ones. Therefore, in July 2014, IPP launched the first Math MOOC on its own platform. This paper describes the requirements, the resulting design and implementation of a mathematics MOOC, which was essentially addressed to three target populations: - pre-college students or individuals wishing to update their Math skills or that need to prepare for the National Exam of Mathematics; - Higher Education students who have not attended in High School, this subject, and who feel the need to acquire basic knowledge about some of the topics covered; - High School Teachers who may use these resources with their students allowing them to develop teaching methodologies like "Flipped Classroom" (available at http://www.opened.ipp.pt/). The MOOC was developed in partnership with several professors from several schools from IPP, gathering different math competences and backgrounds to create and put to work different activities such video lectures and quizzes. We will also try to briefly discuss the advertising strategy being developed to promote this MOOC, since it is not offered through a main MOOC portal, such as Coursera or Udacity.

Keywords: Innovation, Mathematics, MOOCs, Online Learning, Technology in Teaching and Learning.

\section{INTRODUCTION}

Still growing and, somehow, operating in the "behind the curtain", MOOC seem to be carrying out an "open moving wave" in education. The years 2012 [1] and 2013 [2] are often mentioned as "the MOOC years', but the "distance learning/teaching" paradigm goes far beyond our grandparents "era". With all the new technological advances of the "digital era" we are living in, Higher Education Institutions (HEI) are committed to raise the online access, in an opened or internal basis, to all kind of course resources like lecture notes, assessment materials, lecture recordings, among others, trying to take advantage of all the pedagogical/scientific potential these technological developments have to offer, maximizing their scope, while minimizing their eventual, and common, geographical restrictions.

Our institution - Polytechnic Institute of Porto (IPP) is a Higher Education Portuguese institution providing undergraduate and graduate studies. This academic community has more than 20.000 students, teachers and researchers, assigned to one of its seven organic units (School of Engineering (ISEP), School of Accounting and Administration (ISCAP), School of Allied Health Sciences (ESTSP), School of Education (ESE), School of Music and Performing Arts (ESMAE), School of Management 
and Industrial Studies (ESEIG) and School of Management and Technology (ESTGF)) Inside this large academic community there is a constant concern with the definition of strategies related to new ways of teaching and learning, in order to develop students' competences and promote students' academic success and future professional skills. In accordance to these concerns, the e-IPP project e-Learning Unit from Polytechnic of Porto - was born with a generic and globalizing objective: the development and implementation of new ways of teaching/learning/training among the IPP Community and in its area of influence (fundamentally the Porto metropolitan area), with a dynamical and proactive attitude, targeting training needs throughout life, through a continuous learning process, consistent with advances in science and communication technology, enhancing/facilitating/promoting space and time extensions, predominantly, in the long-distance learning domain, either through eLearning or b-Learning and, recently, through "open-Learning".

"Open Educational Resources" (OER), a more general designation, has become a familiar term that we are often confronted with and is being widely discussed on a global level. Any kind of educational materials in the public domain or that is released with an open license that allow users to legally and freely use, copy, adapt, and re-share is considered to be an OER, if we look at UNESCO 2012 Paris Declaration [3], and these resources represent a strategic opportunity to improve the quality of education as well as facilitate policy dialogue, knowledge sharing and capacity building. The Declaration settles the relevance of OER and gives recommendations to governments and educational institutions, among others, around the globe. Consequently, the European Union has started a large-scale initiative on "Opening Up Education". According to the Europe 2020 Strategy [4], "smart growth" points to strengthening knowledge and innovation as driver forces of our future growth. This enrols improvements in the quality of educational systems, the research performance increase, innovation support and knowledge transfer, the promotion of a full and better use of information and communication technologies and to certify that new ideas can be turned into different products and services that generate growth, quality jobs and help to face global social challenges.

Therefore, it is our believe that OER in general, and MOOC in particular, can play an important and differentiating role as an educational resource in this "digital era", as it becomes obvious that we are currently experiencing and facing significant modifications in Higher Education Institutions (HEI), and at all educational levels in general. The way we take advantage of all the new technologies developments, in a constructive knowledge improvement perspective, is a new challenge particularly to all HEl actors, as we must lead and support knowledge sources (and resources), validating processes and performances, "driving" each and every one involved into a proactive attitude towards future.

\section{2 “MATH WITHOUT STRESS” (M100S) PROJECT - DRAFT AND GOALS}

\subsection{General Issues}

All over the planet, the majority of the HEl, particularly those in which Mathematics is a necessary pre requisite for their courses, have to deal and try to tackle an "universal" problem - the difference between the "levels of mathematics knowledge and skills" of their incoming students. Watching the remarkable success that MOOC have been showing and having to deal with this "problem" in our mind, we sensed that students, as well instructors, could only benefit from this new "educational paradigm" in order to, sustainably, take advantage of the existing opportunities to "freely" learn Mathematics online.

IPP launched, in the autumn of 2013, its own MOCC platform - OpenED. This project development gave us the opportunity to create the first IPP MOOC, "baptised" as "Probability and Combinatorics" opening its primary "edition" in May of 2014. With the expansion of this course, we felt that the development of others was imperative and this led us to the second MOOC - "Introduction to Differential Calculus"- having already another one in the "embryonic state" - "Trigonometry and Complex Numbers". In 2015 we formalized a global IPP Math platform named "Math Without STRESS" (or in its original version - in Portuguese - Matemática 100 STRESS - M100S).

\subsection{Objectives}

Our key objective with "M100S - platform" is to develop a handy tool that may contribute to:

- Complement different Mathematics backgrounds of the students, trying to "fill" in the gap between high school and higher education; 
- Offer a friendly system to support the management of each one's learning commitment;

- Help pre-university students to prepare for the National Mathematics Exam;

- Give to the general public the opportunity to refresh and/or exercise any of the available subjects in each developed resource.

These particular courses were chosen also by a combination of other factors:

- Former team experience with Learning Management Systems (LMS) developed in other internal projects (MatActiva Project [5], [6]) and in our own courses;

- Promote the use of new technologies in the learning-teaching process as it may be used as a flipped-classroom basic tool;

- Improve and experience other teaching and learning models, promoting a "doing" methodology.

- Attract new students for IPP - by opening the institution to the general community, trying to reach a more diverse and global audience;

- Increase national and international visibility of the IPP.

\subsection{Courses and Sections}

As we have already mentioned, "Math without Stress" Project is actually developing and supporting three different Courses:

- Probability and Combinatorics

- Introduction to Differential Calculus

- Trigonometry and Complex Numbers

All these courses are created using the same guidelines based on the following division (a small description, of each one of these units will be held in the next section):

- Information Spot

- Math Diagnostic Test (MDT) - entry test, not mandatory;

- Modular subject division with two distinct subsections:

- Video-lectures

- Sequential mini-quizzes;

- "Doubt Ed" - Open Discussion forum;

- Final "Assessment Test"

- Global Course evaluation

In particular, the first course - Probability and Combinatorics - consists of nineteen different modules/lessons, with 19 randomized quizzes and 24 video-lectures, distributed by the following topics:

- Random Experiment and Sample Space

- Events and Operations on Events

- Probability and Properties of Probability

- Exclusive Events

- Conditional Probability

- Law of Total Probability and Bayes Theorem

- Intersection Events

- Fundamental Counting Principle

- Independent Events

- Arrangement without repetition

- Factorial of a Natural Number

- Permutations

- Pascal's Triangle

- Probability Distribution

- Normal Model.

- Arrangement with repetition

- Combinations

- Newton's Binomial Formula

- Binomial Model

All the topics embraced in this and the other three courses developed by the M100S Project, are not "new" for many of our students, since they are covered in high school "Math-A" curricula (but not in Math-B or even MACS - Applied Mathematics to Social Sciences curricula). 


\section{THE COURSE - INTRODUCTION TO DIFFERENTIAL CALCULUS (IDC)}

IDC is the second MOOC course to be released by IPP, accessible to public through OpenED IPP platform. This is a course in a virtual learning open environment open, without mentoring, allowing users a total freedom on their participation "mode", at their own pace and entire flexibility of schedules.

This course "proposal" was based on the Real Functions program sections and respective curricular goals of High School Mathematics, particularly the Math-A curricula ([7], [8], [9], [10]), trying to show and open the way to teach and learn Mathematics. Meanwhile, this was also an opportunity to try to improve student's motivation through a set of interactive materials, in an adaptive format and adaptable to their needs. Thus, its main goal is to encourage and improve the self-study, to stimulate proactive attitudes towards cooperation and interaction between participants, through the open forum and to provide a dynamic and rewarding learning experience.

Since our aim was not only to focus on high school students, we tried to develop an "attractive" course that could encourage and engage anyone interested in Real Functions, Differential Calculus or Mathematics in general. The main page of the IDC course is presented in Fig. 1.

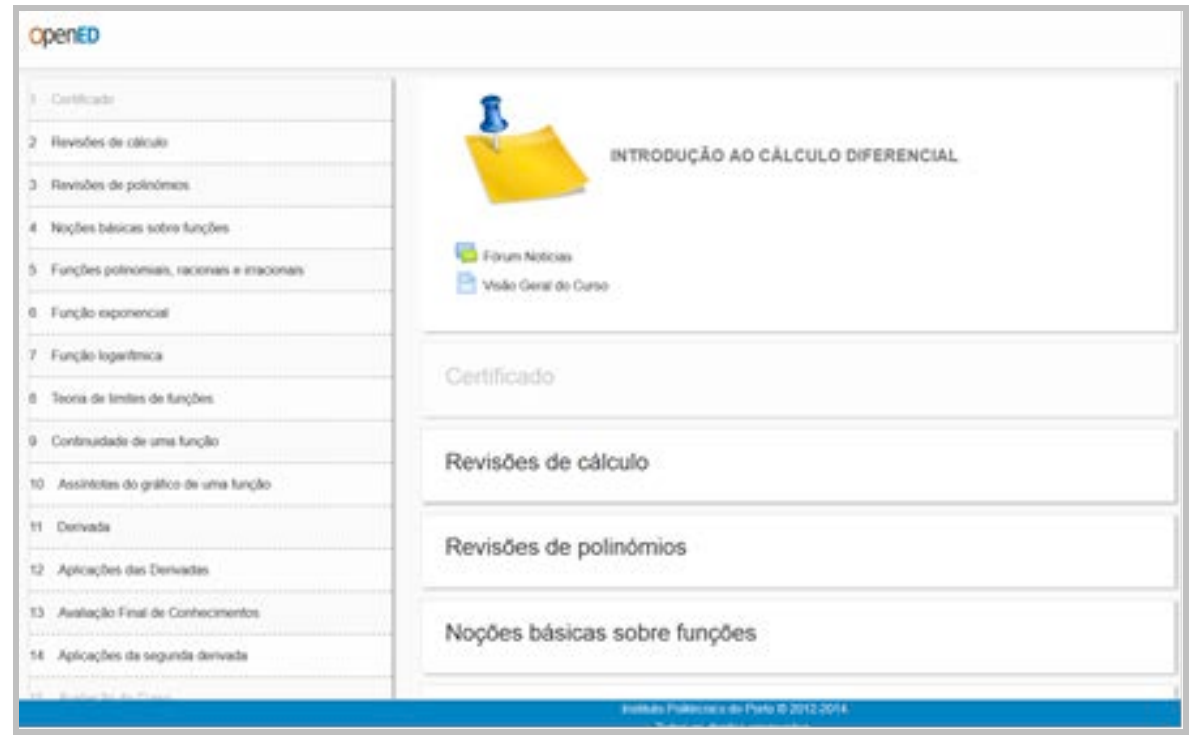

Figure 1 - IDC Course main page screenshot.

The IDC course embraces the following twelve different sections, some of these with more than five modules/lessons spanning six weeks, with a weekly average dedication of three to five hours:

- Basic Calculus review

- Understanding functions

- Exponential Function

- Function Limit Theory

- Asymptotes

- Derivative Applications
- Polynomials Review

- Polynomial, Rational and Irrational Functions

- Logarithmic Function

- Function Continuity

- Function Derivative

- Second Derivative and Applications

As we have already referred, each section, divided in several small modules, has two distinct subsections (Fig.2):

- Video Lectures - addressing the fundamental concepts, accompanied by examples and solved problems - Here we used "Voice Over Presentation" style [11], whose main component is usually a PowerPoint presentation, with several animations, complemented with a voice over explaining the slides. The videos length are between 5 and 10 minutes and were created with Camtasia Studio software for a dynamical editing. According to Sadik [12], both lecture capture and screen casting recordings served as useful supplementary materials for student learning. However, the majority of students preferred the quality and usefulness of the screen casting recordings to lecture capture recordings. Recent research emphasizes that video lectures can provide important benefits to students [13]. 
- Sequential mini quizzes - a group of 5 randomly selected questions, from a question bank specifically created for this course, to be solved for learning consolidation providing successive self-assessment moments - With regard to mini-quizzes, participants can take multiple attempts at each one of them. This can help to turn the quiz into an educational activity instead of a simple assessment. Since all the quizzes are randomized, the student will get a new version in each attempt, which will be useful for practice purposes [14]. Feedback is provided for each question, allowing the students to see a suggested solution, step by step. The Pool of Questions, from which the quizzes are randomised, is categorized separately by learning items (modules) and each section has four subsections, namely: Easy, Medium, Difficult and National Tests/Exams, and has until now more than 350 questions - with respective feedback and suggested solution (Fig.3).
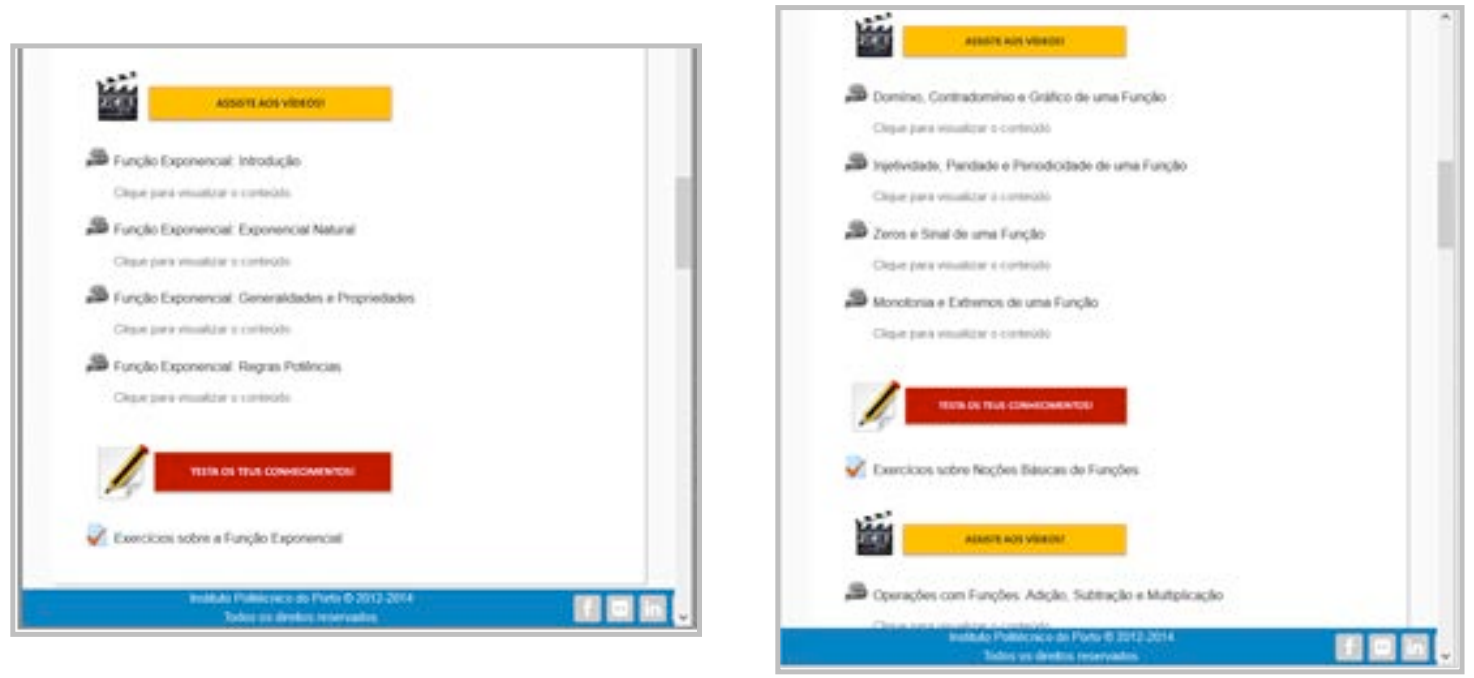

Figure 2 - Screenshot of the structure of "Exponential Function" and part of "Understanding functions" modules.
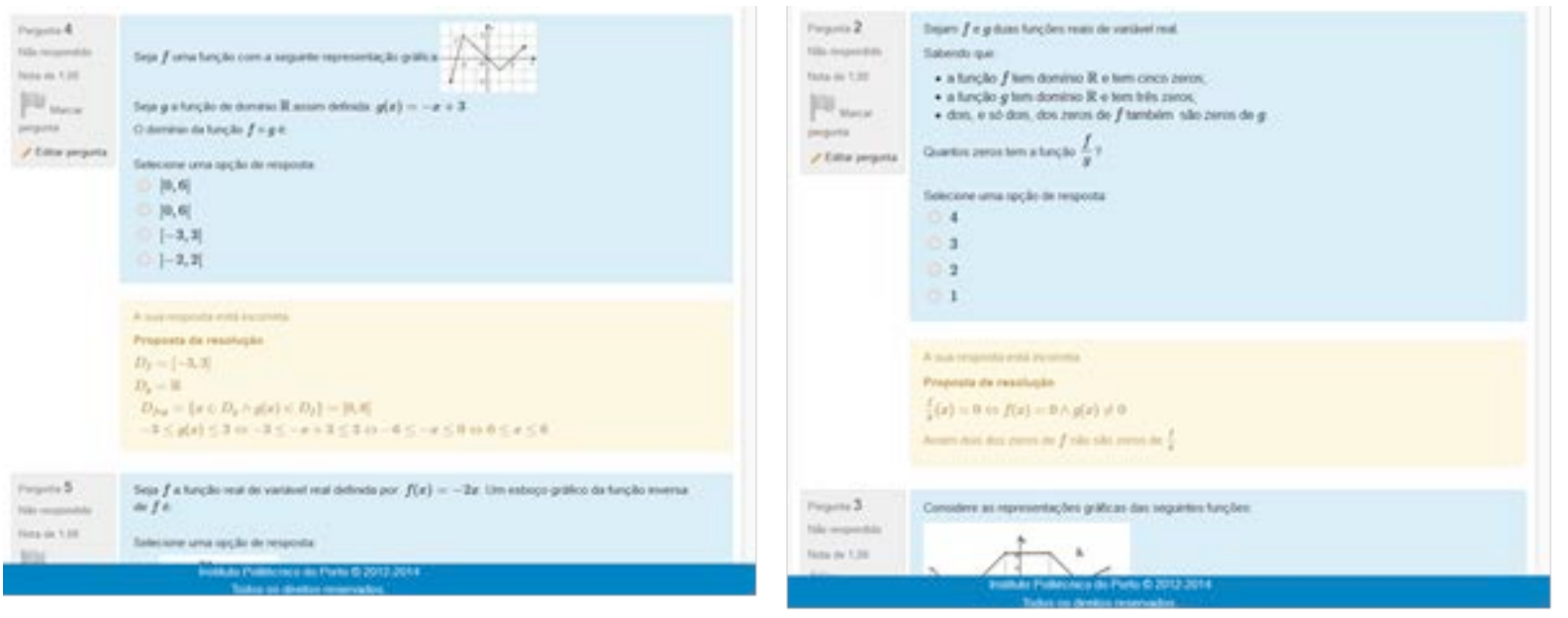

Figure 3 - Questions and feedback screenshot.

There are two kinds of discussion Forums available - Open Forum and "Doubt Ed". The Open Forum works mainly as a forum for discussion among participants. However, to encourage its use, there is an interaction with the team that developed the course. The users can also take advantage of this feature by putting their questions and feeling free to open new discussion topics, as well as they may question instructors and other participants about all kind of doubts they have in course context. In the "Doubt Ed" forum, participants may question instructors and other participants about all kind of doubts they have strictly in course context. Note that, there is no limit to the number of discussion topics that can be opened in a course, so it is important that the forums have an almost direct and synchronised follow up in order to be well organised and "profitable". 
In the "end" of this IDC course, participants can take a Final Knowledge 20 questions Assessment Test, which can be "redone" three times, at most. The participant may get a Participation Certificate if the quantitative result obtained in this test is equal or greater than $75 \%$. All materials, including layout, design, content, pool of questions, animated mascot, the Project Logo, etc., were created from scratch for this course.

\section{THE M100S TEAM CHALENGES}

M100S Project is one, and virtually the only, venture that managed to gather and put to work together, in an open cooperation scheme, professors from all the different Organic Units of IPP, where the scientific area of Mathematic exists. Historically, all these Math professors have different backgrounds, in terms of scientific formation, teaching various courses (courses in bachelor or master degrees in Engineering, Accounting, Management, Tourism, Basic Education, among others) and experiencing different working habits and schedules. The actual team has close to twenty members namely: Ana Paula Lopes (ISCAP); Cristina Torres (ISCAP); Eduarda Pinto Ferreira (ISEP); Eliana Costa e Silva (ESTGF); Filomena Soares (ESEIG); Hermínia Ferreira (ISEP); Isabel Vieira (ISCAP); Jorge Mendonça (ISEP); José Azevedo (ISCP); Lurdes Babo (ISCAP); Maria João Polidoro (ESTGF); Marisa Oliveira (ISEP); Marta Amorim (ISEP); Paula Nunes (ESEIG); Sidonie Costa (ESTGF) e Susana Nicola (ISEP), until now...

All these Math IPP professors, whose work permitted, and still does, the complete development of these MOOC Courses, are volunteers, doing all the work (reviewing and reediting all the digital learning objects and contents) pro bono, in their own free time..

The enormous amount of work was divided in two different parts, with several different steps each. For Video creation it was considered:

- Development of Dynamic Presentations for Video support;

- Scientific review of presentations;

- Video and audio recording;

- Video editing;

- Videos review.

Relative to the "Question Bank" development the various steps enrolled were:

- Questions collection and compilation;

- Proposed solution and questions resolution preparation;

- Edition of Proposed resolution

- Questions introduction in the MOOC platform;

- Introduction of the proposed feedback for all the questions in the MOOC platform;

It is also important to state that the development of this MOOC platform was led by an enthusiastic team that "rolled up the sleeves" to create the several courses from scratch, without almost any resources available, lacking any hope of institutional recognition, even from the respective organic units. It should also be noted that this project won, at the beginning of the 2015 year, an award "PIPED - Pedagogical Innovation Award for Distance Learning".

\section{CONCLUSION}

Math 100 Stress Project, arose after a careful analysis on the structured formative offer and finding a considerable gap in available materials in Portuguese (from Portugal), when compared with the extension of digital offer in "Brazilian", whose terminology is not always coincident, triggering various issues in terms of learning and respective connections.

We couldn't finish this short text without mentioning that, despite MOOC have "awoke" the HEI to a new reality, it is still little explored in Portugal, there are still several open questions, even on an international scale: - funding source - being open and free, how can they be financially sustainable? The promotional vision has been the first "engine" for these courses development, but they often dependent on the goodwill of their "creators", as in our case. - Certification - this is an issue that backs the fact that many MOOC are not truly MOOC, since they demand a "financial contribution", in 
order to be certified. - Operating Format - self-sufficient or minimally managed (even from a distance)? Course duration? Type of content available? Copyright? We feel it is urgent to analyze and research to support and guide the discussion, trying to get answers to these and many other issues.

\section{REFERENCES}

[1] Pappano, L. (2012, November). The year of the MOOC. The New York Times. Retrieved from http://www.nytimes.com/2012/11/04/education/edlife/massive-open-online-courses-aremultiplying-at-a-rapid-pace.html

[2] Booker, E. (2013, January). Is 2013 year of The MOOC? Information Week. Retrieved from http://www.informationweek.com/education/online-learning/is-2013-year-of-themooc/240146431

[3] UNESCO (2012). UNESCO Releases the 2012 Paris OER Declaration at the World Open Education Resources (OER) Congress. Retrieved from, http://unesco.usmission.gov/oercongress-2012.html

[4] EUROPE 2020 (2010). A European strategy for smart, sustainable and inclusive growth. Retrieved from http://ec.europa.eu/eu2020/pdf/COMPLET\%20EN\%20BARROSO $20 \% 20 \% 20007 \% 20$ \%20Europe\%202020\%20-\%20EN\%20version.pdf

[5] Babo, L., J. Azevedo, Lopes, A. (2008). The Active Mathematics Project at ISCAP. ENMA2008 International Conference on Engineering and Mathematics Proceedings Book ISBN: 978-84612-5331-9, 2008.

[6] Lopes, A., Babo, L., Azevedo, J. (2008). Teaching and Learning Mathematics Using Moodle. INTED2008 CD Proceedings ISBN: 978-84-612-0190-7.

[7] DGE (2001). Matemática A - $10^{\circ}$ Ano. Programas e Orientações Curriculares - DGE - Direção Geral da Educação - Ministério da Educação e Ciência. Retrieved from http://www.dge.mec.pt/sites/default/files/Secundario/Documentos/Documentos_Disciplinas_nov o/Curso_Ciencias_Tecnologias/Matematica_A/matematica_a_10.pdf

[8] DGE (2002). Matemática A - $11^{\circ}$ Ano. Programas e Orientações Curriculares - DGE - Direção Geral da Educação - Ministério da Educação e Ciência. Retrieved from http://old.dge.mec.pt/metascurriculares/data/metascurriculares/E_Secundario/C_C_Humanistic os/matematica_a_11.pdf

[9] DGE (2002). Matemática A - $12^{\circ}$ Ano. Programas e Orientações Curriculares - DGE - Direção Geral da Educação - Ministério da Educação e Ciência. Retrieved from http://www.dge.mec.pt/sites/default/files/Secundario/Documentos/Documentos_Disciplinas_nov o/Curso_Ciencias_Tecnologias/Matematica_A/matematica_a_12.pdf

[10] MEC (2014). Programa e Metas Curriculares de Matemática A - Ensino Secundário. DGE Direção Geral da Educação - Ministério da Educação e Ciência. Retrieved from http://www.dge.mec.pt/sites/default/files/Secundario/Documentos/Documentos_Disciplinas_nov o/Curso_Ciencias_Tecnologias/Matematica_A/programa_metas_curriculares_matematica_a_s ecundario.pdf

[11] Vieira, I., Lopes, A.P. and Soares, F. (2014). The Potential Benefits of Using Videos in Higher Education. EDULEARN14 CD Proceedings ISBN:978-84-617-0557-3.

[12] Sadik, A. (2015). Student Preferences for Types of Video Lectures: Lecture Capture vs. Screencasting Recordings. International Journal of Higher Education Vol. 4, No. 4; pp.94-104, 2015.

[13] Giannakos, M., Chorianopoulos, K., Chrisochoides, N. (2015). Making sense of video analytics: Lessons learned from clickstream interactions, attitudes, and learning outcome in a videoassisted course. The International Review of Research in Open and Distributed Learning, 16(1). Retrieved from http://www.irrodl.org/index.php/irrodl/rt/printerFriendly/ 1976/3198.

[14] Torres, C., Lopes, A., Babo, L., Azevedo, J. (2011). Improving Multiple - Choice Questions. Volume 1, No.1, US-China Education Review, Education Theory, David Publishing ISSN 21616248 , USA. 